\title{
Pemanfaatan Abu Limbah Bonggol Jagung Sebagai Bahan Substitusi Filler Untuk Campuran $A C$-WC
}

\author{
Arjuna Sanda Sau'langi*1, Alpius*2, Herman Welem Tanje ${ }^{3}$ \\ *1 Mahasiswa Program Studi Teknik Sipil, Universitas Kristen Indonesia Paulus Makassar, \\ Indonesia arjunasanda26@gmail.com \\ *2,3 Dosen Program Studi Teknik Sipil, Universitas Kristen Indonesia Paulus Makassar, Indonesia ${ }^{2}$ \\ alpiusnini@gmail.com $^{* 2}$ dan $\underline{\text { hwtanje@ }}$ ukipaulus.ac.id $^{* 3}$
}

Corresponding Author: $\underline{\text { hwtanje@ukipaulus.ac.id }}$

\begin{abstract}
Abstrak
Campuran aspal dapat dimodifikasi dengan menambahkan berbagai jenis campuran, mulai dari bahan tambahan kimia, bahan alam, dan limbah sisa. Penelitian ini dimaksudkan untuk mengetahui karakteristik campuran $A C$ - WC yang memakai abu bonggol jagung menjadi material substitusi filler. Metode yang digunakan yaitu melakukan serangkaian tes karakteristik filler abu bonggol jagung lalu pembuatan benda uji campuran $A C$-WC serta pengujian marshall. Dari pengujian karakteristik campuran AC-WC diperoleh Stabilitas 0\%-100\% : 1110.17kg - 1436.40kg untuk Flow 0\%-100\%: $2.41 \mathrm{~mm}-3.47 \mathrm{~mm}$ untuk VIM 0\%-100\% : $3.21 \%-4.16 \%$ untuk VMA 0\%-100\% : $14.56 \%-15.72 \%$ dan untuk $V F B$ 0\%-100\% : 73.55\% - 77.96\%. Dari hasil pengujian dapat disimpulkan bahwa campuran $A C$-WC dengan substitusi filler abu bonggol jagung yang memenuhi sepesifikasi umum bina marga 2018 adalah dari kadar 0\%-60\%.
\end{abstract}

Kata kunci: Filler, AC-WC, Abu, Bonggol, Jagung

\begin{abstract}
Asphalt mixtures can be modified by adding different types of mixtures, ranging from chemical additives, natural materials, and waste waste. This study was intended to find out the characteristics of ac-wc mixtures that use corn weevil ash into filler substitution material. The method used is to perform a series of characteristic tests of corn weevil ash fillers and then the manufacture of AC-WC mixed test objects and marshall testing. From testing the characteristics of the AC-WC mixture obtained Stability 0\%-100\%: $1110.17 \mathrm{~kg}-1436.40 \mathrm{~kg}$ for Flow 0\%-100\%: $2.41 \mathrm{~mm}-3.47 \mathrm{~mm}$ for VIM $0 \%-100 \%: 3.21 \%$ - $4.16 \%$ for VMAs 0\%-100\%: $14.56 \%-15.72 \%$ and for VFB 0\%-100\%: $73.55 \%$ 77.96\%. From the test results it can be concluded that the mixture of AC-WC with the substitution of corn weevil ash fillers that meet the general specification of bina marga 2018 is from a rate of 0\%$60 \%$.
\end{abstract}

Keywords: Filler, AC-WC, Ash, Weevil, Corn

\section{PENDAHULUAN}

Peran semen sebagai filler pada campuran aspal beton khususnya pada campuran $A C$ - $W C$ sangat penting karena semen sebagai filler berfungsi sebagai bahan pengisi rongga pada campuran aspal beton. Campuran aspal dapat dimodifikasi dengan menambahkan berbagai jenis campuran, mulai dari bahan tambahan kimia, bahan alam, dan limbah sisa. Menurut Badan Pusat Statistik (BPS), produksi jagung di Indonesia mencapai 19.612.435 ton, sehingga limbah jagung yang dihasilkan dalam jumlah besar dapat mencemari lingkungan. 
Bonggol jagung yang sudah tidak digunakan ternyata dapat digunakan sebagai bahan substitusi semen karena bonggol jagung yang dibakar dan menjadi abu mengandung senyawa $\mathrm{SiO} 2$ yang memiliki kerekatan yang sama seperti semen. Kandungan senyawa silika ( $\mathrm{SiO} 2)$ yang abu bonggol jagung memiliki kesamaan senyawa semen sehingga abu bonggol jagung dapat dijadikan alternatif sebagai bahan substitusi filler [1]. Hal inilah yang mendorong pemanfaatan abu bonggol jagung sebagai bahan substitusi filler.

Jenis lapisan aspal beton (LASTON) adalah jenis lapisan perkerasan lentur, lapisan ini terbuat dari agregat dan aspal yang menjadi material pengikat, dan dicampur merata dalam kondisi temperatur tertentu. "Laston dibagi menjadi tiga jenis yaitu Laston untuk lapisan Aus atau disebut juga $A C$-WC (Asphalt concrete Wearing Course). Laston untuk lapisan pengikat atau disebut juga $A C-B C$ (Asphalt Concrete - Binder Course), dan Laston untuk lapisan pondasi atau disebut juga AC-Base (Asphalt Concrete - Base) [2] [3]

Filler pada campuran aspal beton khususnya pada campuran $A C$-WC sangat penting karena filler berfungsi sebagai bahan pengisi rongga pada campuran aspal beton. Abu bonggol jagung adalah limbah dari hasil pertanian yang mengandung unsur silika yang dapat dimanfaatkan untuk bahan substitusi parsial semen dalam campuran. Abu bonggol jagung didapatkan dari bonggol jagung yang telah diambil bulir jagungnya kemudian dibakar sehingga menjadi abu bonggol jagung. Pembakaran bonggol jagung yang menciptakan abu yang mengandung bahan aluminium dan silika yang bereaksi dengan kalsium oksida dalam pasta semen dan saling menempel, dapat memungkinkan terbentuknya bahan yang kuat untuk meningkatkan kualitas beton. Limbah bonggol jagung memiliki kandungan unsur silika yang cukup tinggi yakni 66,38\% [4].

Beberapa penelitian sejenis terdahulu diantaranya Pengujian Batu Apung Sebagai Filler pada Campuran HRS -WC [5]. Hasil penelitian menunjukkan bahwa karakteristik abu batu apung memenuhi spesifikasi sebagai bahan pengganti filler pada campuran Lataston HRS-WC gradasi senjang dan semi senjang. Melalui uji Marshall diperoleh karakteristik campuran Lataston HRS-WC bergradasi senjang dan semi senjang dengan kadar aspal 6,75\%. Hasil pengujian Marshall Immertion campuran Lataston HRS-WC bergradasi senjang dan semi senjang dengan kadar filler optimum 100\% mendapatkan Indeks Perendaman (IP) / Indeks Kekuatan Sisa (IKS) / Durabilitas campuran sebesar 95,73\% dan 96,66\% yang artinya campuran tersebut tahan terhadap suhu, lamanya terendam air. Pemanfaatan Agregat Sungai Mawa Kecamatan Cendana dalam Campuran AC-WC [6]. Pemanfaatan Agregat Sungai Lamasi Kabupaten Luwu Sebagai Campuran Lapisan Aspal Beton AC-WC [7]. Pemanfaatan Batu Sungai Melli Kecamatan Baebunta Kabupaten Luwu Utara Dalam Campuran AC-WC [8]. Pemanfaatan Batu Gunung Pasapak Kecamatan Bambang Kabupaten Mamasa sebagai Agregat Campuran Laston WC [9]. Karakteristik Campuran Laston Lapis Antara Menggunakan Abu Jerami Sebagai Bahan Substitusi Filler [10]. Hasil penelitian menunjukkan bahwa stabilitas, flow, VIM, VMA, dan VFB pada kadar abu jerami 0\%, 25\%, 50\% memenuhi spesifikasi Bina marga 2018, sedangkan VMA pada kadar abu jerami $75 \%$ tidak memenuhi spesifikasi Bina marga 2018, dan VMA, VFB pada kadar abu jerami 100\% juga tidak memenuhi spesifikasi Bina marga 2018. Variasi Suhu Pemadatan Campuran AC-WC Menggunakan Batu Sungai Balusu Kabupaten Toraja Utara [11].

Tujuan penelitian ini adalah untuk mengetahui karakteristik filler dari abu bonggol jagung, karakteristik marshall pada campuran $A C$-WC yang memakai batu Sungai Sadang dan abu bonggol jagung menjadi material substitusi filler, dan pengaruh kadar abu bonggol jagung sebagai bahan substitusi filler terhadap karakteristik campuran $A C$-WC yang memakai batu Sungai Sadang. 


\section{METODOLOGI}

\section{Lokasi Pengambilan Material}

Lokasi tempat pengambilan material diambil dari Batupapan yang terletak di Kecamatan Makale Kabupaten Tana Toraja. Material yang terdapat di Batupapan banyak memberikan kontribusi untuk mendukung pembangunan daerah. Rute akses ke material ini terletak $\pm 100 \mathrm{~m}$ dari jalan raya Tritura, dan belum bisa menggunakan kendaraan, sehingga perlu berjalan kaki melewati persawahan untuk menuju ke lokasi pengambilan agregat.

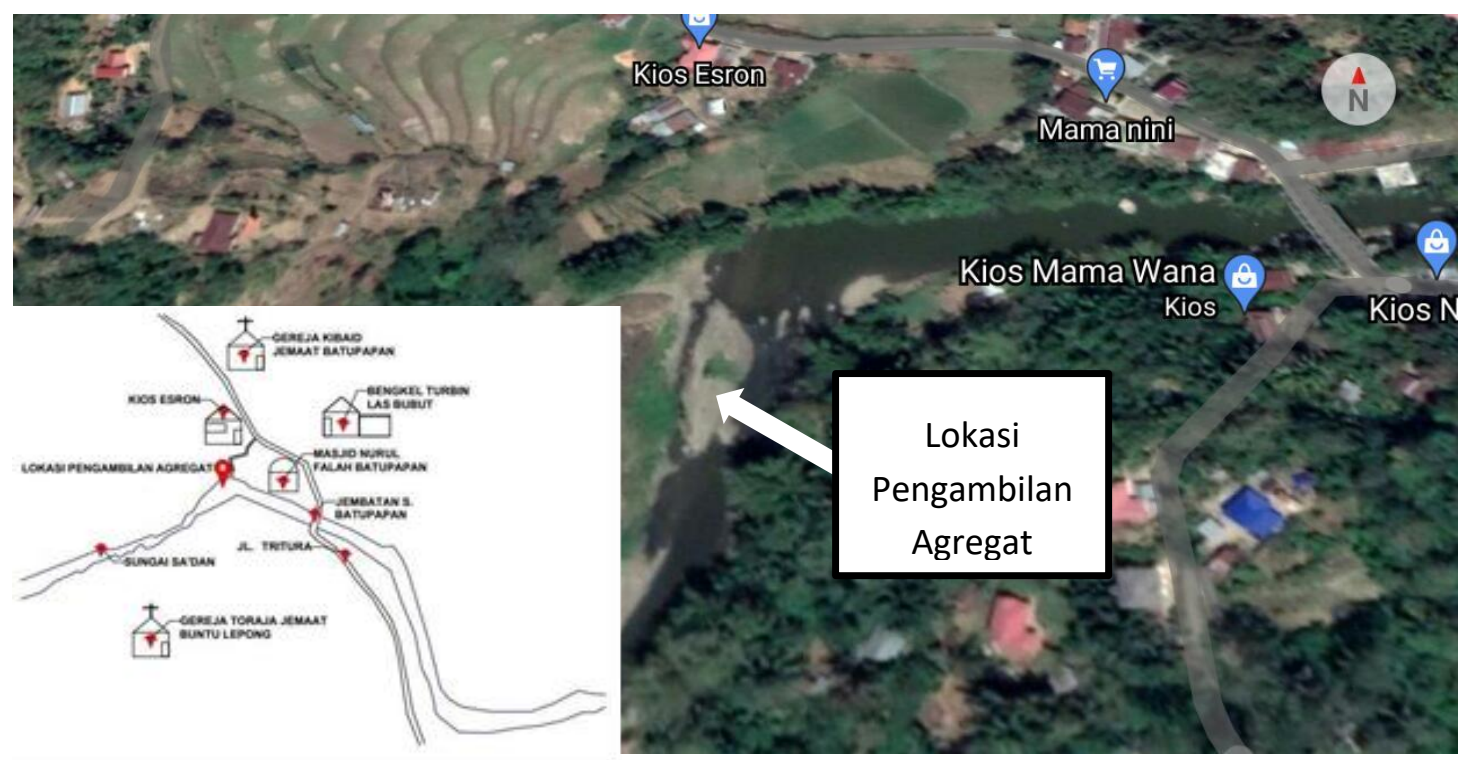

Gambar 1. Lokasi pengambilan agregat (-4 54' 53.1” N 119० 50' 24.2” E)

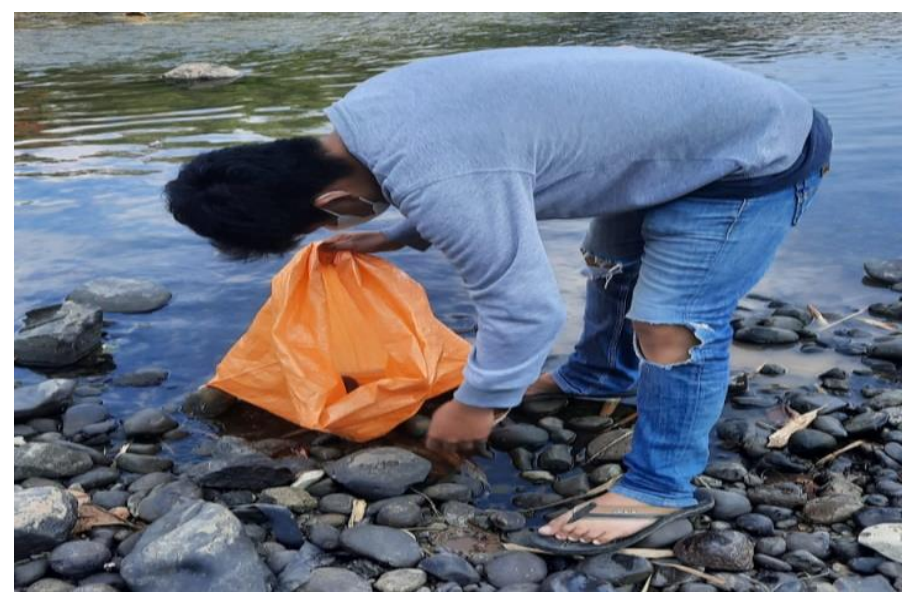

Gambar 2. Proses pengambilan agregat

\section{Perancangan Komposisi Campuran $A C$ - $W C$}

Material yang digunakan pada rancangan komposis campuran $A C$-WC Antara ini adalah sebagai berikut.

1. Agregat yang diperoleh dari batu Sungai Sadang Kabupaten Tana Toraja

2. Aspal pengikat (aspal penetrasi 60/70). 


\section{Bahan substitusi filler berasal dari abu bonggol jagung.}

Komposisi campuran AC-WC menggunakan komposisi dari hasil penelitian Yance Panggalo (2020) dengan menambahkan abu bonggol jagung sebagai bahan substitusi filler semen yang sesuai dengan persyaratan Spesifikasi Umum Bina Marga 2018

\section{Tabel 1. Komposisi Gradasi Campuran $A C$ - $W C$}

\begin{tabular}{cccc}
\hline $\begin{array}{c}\text { Nomor Saringan } \\
(\mathbf{m m})\end{array}$ & Spesifikasi & $\begin{array}{c}\text { Rancangan } \\
\text { Gradasi }\end{array}$ \\
\hline $1 \frac{1}{2}$ & 37,5 & & \\
\hline 1 & 25 & & \\
\hline $3 / 4$ & 19 & 100 & 100 \\
\hline $1 / 2$ & 12,5 & $90-100$ & 95 \\
\hline $3 / 8$ & 9,5 & $77-90$ & 83,5 \\
\hline 4 & 4,75 & $53-69$ & 61 \\
\hline 8 & 2,36 & $33-53$ & 43 \\
\hline 16 & 1,18 & $21-40$ & 30,5 \\
\hline 30 & 0,6 & $14-30$ & 22 \\
\hline 50 & 0,3 & $22-$ Sep & 15,5 \\
\hline 100 & 0,15 & $15-J u n$ & 10,5 \\
\hline 200 & 0,075 & $9-A p r$ & 6,5 \\
\hline
\end{tabular}

\section{Perhitungan Kadar Aspal Perkiraan Awal Untuk $A C$-WC}

Kadar aspal yang digunakan adalah kadar aspal terendah yaitu 5,50\% dari hasil penelitian Yance Panggalo (2020). Kadar aspal 5,50\% adalah kadar aspal dimana hasil pengujian sebelumnya memiliki rongga paling besar dalam campuran $A C$-WC yang menggunakan agregat batu Sungai Sadang dengan komposisi abu bonggol jagung dan semen yaitu 0\% : 100\%, 20\% : 80\%, 40\%: 60\%, 60\%: 40\%, $80 \%: 20 \%$, dan 100\% : $0 \%$ dari berat filler.
Berat Aspal (gr)

$$
=\frac{\text { Kadar aspal }}{\text { Kadar aspal maks }}
$$

Untuk kadar aspal 5,50\%:

$$
\begin{aligned}
\operatorname{Berat} \text { Aspal }(\mathrm{gr}) & =\frac{5,50}{100} \times 1200 \\
& =66 \mathrm{gram}
\end{aligned}
$$

\section{Persiapan Sampel Campuran $A C$-WC}

Jenis campuran benda uji yang digunakan dalam pengujian Marshall ini merupakan campuran aspal panas (Hot Mix) AC-WC yang berjumlah 18 buah dengan takaran perbandingan filler antara filler abu bonggol jagung dan filler semen sebagai berikut 0\%:100\%, 20\%:80\%, 40\%:60\%, 60\%: 40\%, 80\%: 20\%, dan 100\% : 0\% dengan kadar aspal 5,50\% yang berjumlah 3 buah sampel untuk masing-masing perbandingan takaran filler. 
Tabel 2. Jumlah Benda Uji

\begin{tabular}{ccc}
\hline $\begin{array}{c}\text { Kadar Aspal } \\
(\boldsymbol{\%})\end{array}$ & $\begin{array}{c}\text { Kadar Abu Bonggol } \\
\text { Jagung }(\boldsymbol{\%})\end{array}$ & $\begin{array}{c}\text { Jumlah Benda } \\
\text { Uji }\end{array}$ \\
\hline \multirow{3}{*}{5.5} & 0 & 3 \\
\cline { 2 - 3 } & 20 & 3 \\
\cline { 2 - 3 } & 40 & 3 \\
\cline { 2 - 3 } & 60 & 3 \\
\cline { 2 - 3 } & 80 & 3 \\
\hline & 100 & $\mathbf{1 8}$ \\
\hline
\end{tabular}

\section{Pemeriksaan/Pengujian Campuran AC-WC Menggunakan Marshall Konvensional}

Pengujian marshall konvensional yang dilakukan mengacu pada SNI 06-2489-1991 dengan sampel campuran $A C$-WC dan abu bonggol jagung sebagai bahan substitusi filler. Dari pengujian marshall konvensional diperoleh data karakteristik campuran aspal dengan perbandingan filler antara filler abu bonggol jagung dan filler semen yaitu berupa data pengukuran berat jenis, pengukuran stabilitas dan flow, serta pengukuran kerapatan dan analisa rongga.

\section{ANALISA DAN PEMBAHASAN}

\section{Karakteristik campuran}

\section{a. Analisis terhadap Stabilitas}

Penambahan abu bonggol jagung sebagai bahan substitusi filler semen, dari kadar abu bonggol jagung 0\%, $20 \%, 40 \%$, dan $60 \%$ menggunakan kadar aspal 5,50\% pada campuran dapat membentuk ikatan antar agregat (Interlocking) yang disebabkan oleh abu bonggol jagung dan semen yang mengisi rongga, yang mengakibatkan campuran memliki rongga yang sedikit sehingga aspal dapat mengikat dan mengisi rongga yang terdapat pada campuran dan membuat campuran semakin padat dan kuat dan menyebabkan stabilitas campuran menjadi besar, tetapi penambahan kadar abu bonggol jagung dari 80\% dan 100\% membuat ikatan agregat menjadi lemah karena ketika menambahkan abu bonggol jagung yang lebih banyak dari semen yang menyebabkan semakin banyak rongga agregat yang diisi oleh abu bonggol jagung mengakibatkan aspal sulit untuk mengikat agregat dan menyebabkan stabilitas campuran menjadi kecil.

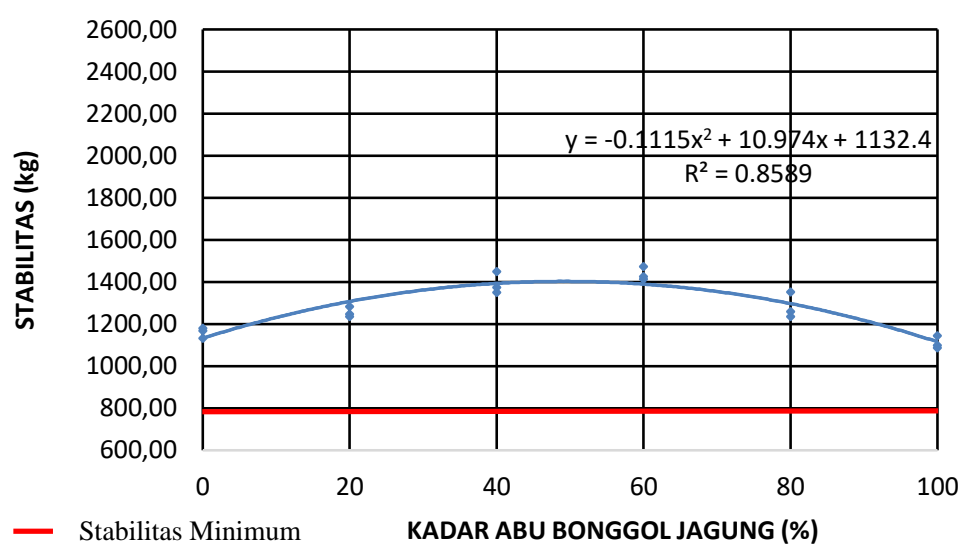


Gambar 3. Hubungan Kadar Abu Bonggol Jagung Terhadap Stabilitas

\section{b. Analisa terhadap VIM (Void in Mix)}

Semakin tinggi kadar abu bonggol jagung yang dipakai menyebabkan nilai VIM menjadi kecil. Dan juga sebaliknya, apabila kadar abu bonggol jagung yang dipakai lebih kecil menyebabkan nilai VIM menjadi besar, hal ini di sebabkan oleh abu bonggol jagung yang berfungsi mengurangi volume rongga udara dalam campuran yang mengakibatkan rongga udara pada campuran menjadi kecil.

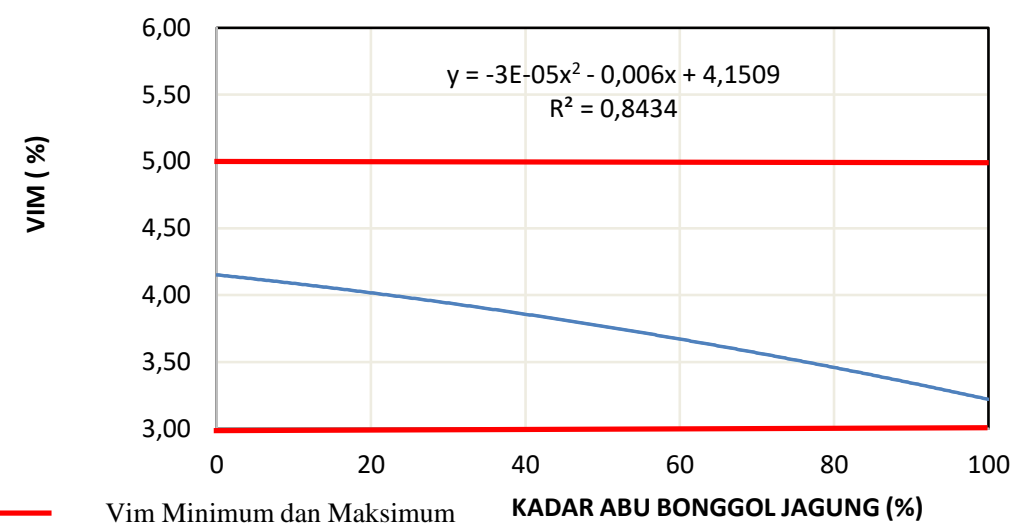

Gambar 4. Hubungan Kadar Abu Bonggol Jagung terhadap VIM

\section{c. Analisa terhadap Flow}

Pemakaian abu bonggol jagung pada campuran aspal yang lebih banyak, akan menyebabkan rongga dalam campuran menjadi lebih banyak terisi oleh aspal, hal ini yang mengakibatkan kelelehan mengalami penurunan, akan tetapi penambahan abu bonggol jagung yang terlalu banyak hingga melewati kadar abu bonggol jagung $60 \%$ akan menyebabkan sulitnya aspal saling mengikat dengan agregat karena kurangnya kemampuan abu bonggol jagung untuk mengikat aspal dan agregat dibandingkan dengan semen.

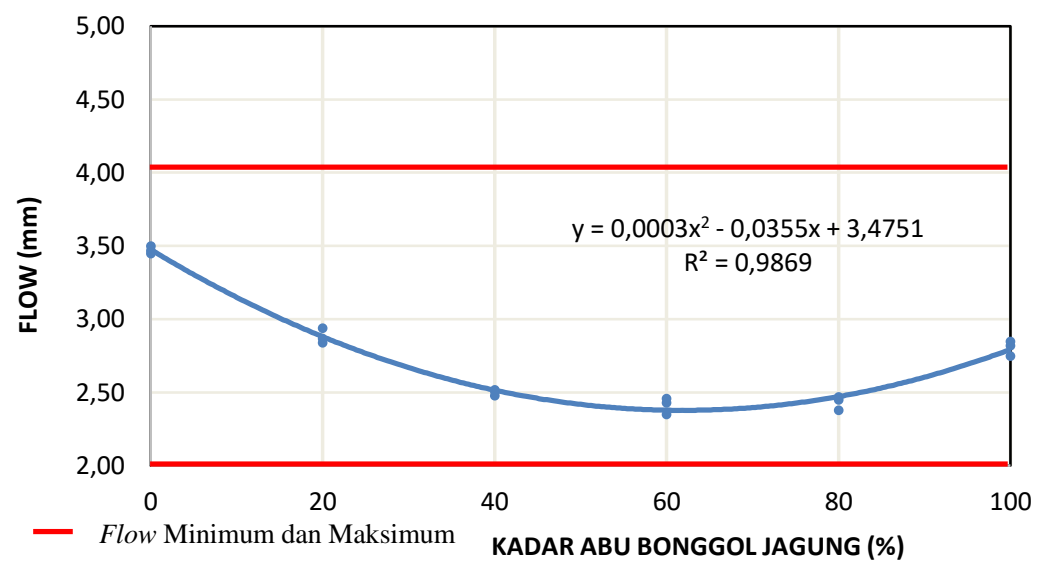

Gambar 5. Hubungan Kadar Abu Bonggol Jagung Terhadap Flow

\section{d. Analisa terhadap VMA (Void in Mineral Aggregate)}

Semakin bertambahnya kadar abu bonggol jagung yang di gunakan dapat membuat rongga antar agregat yang diisi oleh abu bonggol jagung semakin besar mengakibatkan nilai VMA akan menurun. Hal ini di diakibatkan oleh abu bonggol jagung telah mengisi rongga antar agregat, membuat rongga antar agregat 
semakin kecil, dan juga seperti yang di lihat untuk kadar abu bonggol jagung $80 \%$ dan $100 \%$ yang tidak memenuhi spesifikasi, karena kadar abu bonggol jagung dalam jumlah berlebihan dapat menyebabkan aspal sulit untuk menyelimuti agregat dan akan mengakibatkan aspal sulit untuk mengikat.

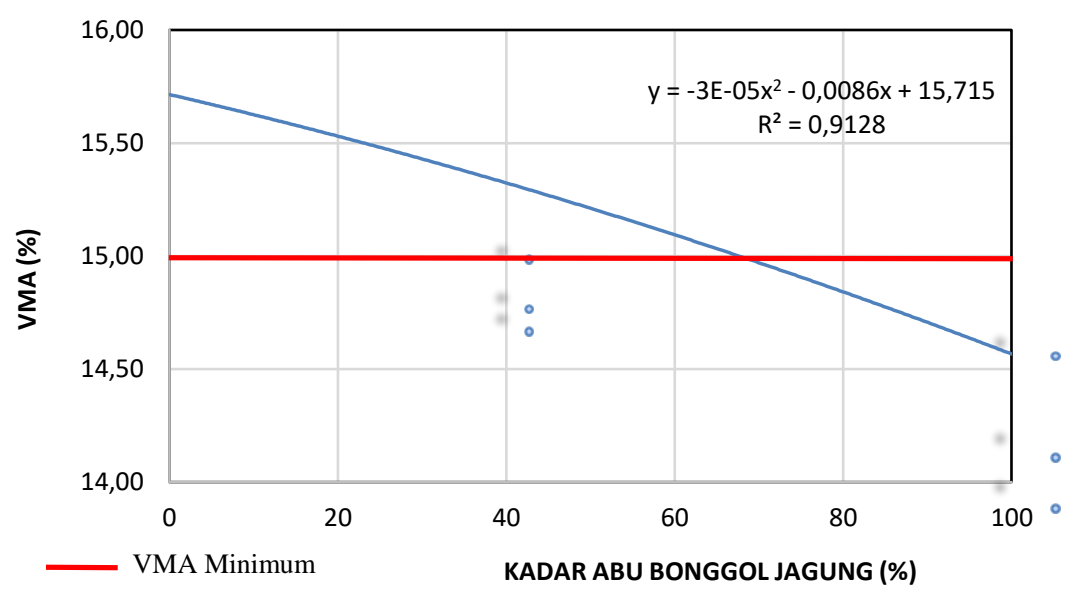

Gambar 6. Hubungan Kadar Abu Bonggol Jagung terhadap VMA

\section{e. Analisa terhadap VFB (Void Filled with Bitumen)}

Penggunaan kadar abu bonggol jagung yang semakin bertambah akan meningkatkan nilai $V F B$, hal ini desebabkan oleh kenaikkan kadar abu bonggol jagung pada campuran mengakibatkan rongga-rongga pada campuran semakin sedikit tetapi aspal masih dapat mengisi rongga yang mengakibatkan nilai $V F B$ mengalami peningkatan yang disebabkan oleh penambahan kadar abu bonggol jagung.

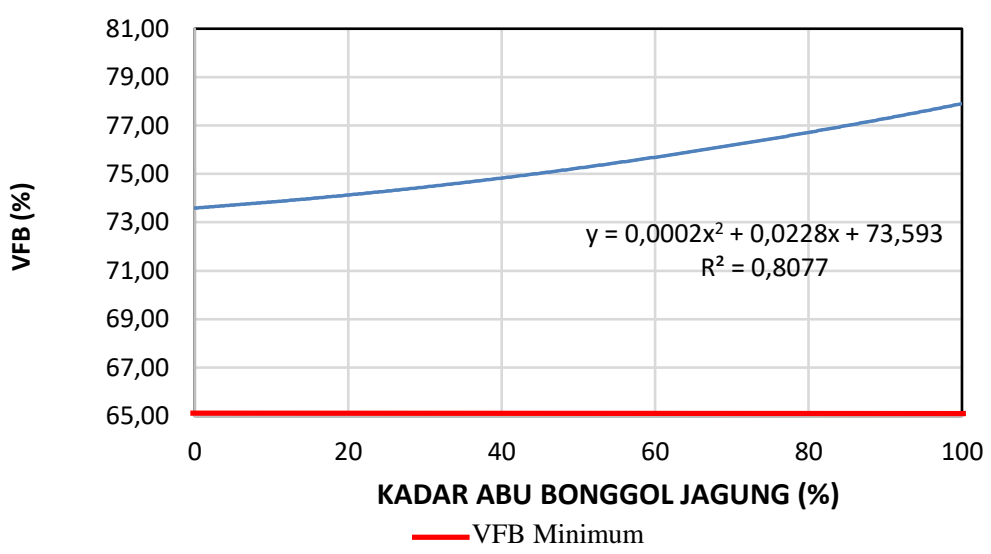

Gambar 7. Hubungan Kadar Abu Bonggol Jagung terhadap VFB

\section{KESIMPULAN}

1. Dari pengujian karakteristik filler abu bonggol jagung berupa pengujian berat jenis diperoleh nilai berat jenis abu bonggol jagung yaitu 1,929 yang masih memenuhi Standar Spesifikasi Umum Bina Marga 2018 karena pada Standar Spesifikasi Umum Bina Marga 2018 tidak mencantumkan nilai batasan untuk berat jenis filler. 
2. Melalui uji marshall dapat diketahui bahwa campuran $A C$-WC dengan substitusi abu bonggol jagung dengan kadar abu bonggol jagung 0\% hingga 60\% masih memenuhi Standar Spesifikasi Umum Bina Marga 2018 sedangkan 80\% dan 100\% tidak memenuhi Standar Spesifikasi Umum Bina Marga 2018 dengan nilai stabilitas $1087.28 \mathrm{~kg}-1472.31 \mathrm{~kg}$, nilai flow $2.35 \mathrm{~mm}-3.5 \mathrm{~mm}$, nilai VIM $3.10 \%-4.22 \%$, nilai VMA $14.46 \%$ - $15.78 \%$, dan nilai VFB $73.23 \%-78.55 \%$.

3. Pengaruh bertambahnya kadar abu bonggol jagung dari $0 \%, 20 \%, 40 \%, 60 \%, 80 \%$ dan $100 \%$ sangat berpengaruh terhadap nilai stabilitas, flow, VIM, VMA, dan VFB karena semakin bertambahnya abu bonggol jagung akan mengakibatkan sulitnya partikel agregat saling mengikat dengan aspal karena dominannya abu bonggol jagung dalam campuran karena kurangnya kemampuan abu bonggol jagung untuk mengikat agregat dibandingkan dengan semen oleh karena itu pada kadar abu bonggol jagung $80 \%$ dan 100\% tidak memenuhi Standar Spesifikasi Umum Bina Marga 2018.

\section{DAFTAR PUSTAKA}

[1] A. Kusuma, "Material Subtitusi Filler," dalam Pemanfaatan Material Alternatif (Sebagai Bahan Penyusun Konstruksi), Makassar: CV. Tohar Media, 2021, hlm. 121-130.

[2] G. Rusbintardjo, Aspal- Bahan Perkerasan Jalan, 1 ed. Semarang: UNISSULA Press, 2013.

[3] R. Rachman, "Pemanfaatan Batu Gunung Bottomale Toraja Utara sebagai Campuran Laston," J. Tek. Sipil Dan Teknol., vol. 6, no. 1, hlm. 20-30, 2020.

[4] D. A. Adesanya dan A. A. Raheem, "Development of corn cob ash blended cement," Constr. Build. Mater., vol. 23, no. 1, hlm. . 347-352, 2009.

[5] S. Yanti, Rosiana, D. Sandy, dan Alpius, "Pengujian Batu Apung Sebagai Filler pada Campuran HRS -WC.," Paulus Civ. Eng. J., vol. 1, no. 2, hlm. 28-36.

[6] I. S. K. Sosang, Alpius, dan Elisabeth, "Pemanfaatan Agregat Sungai Mawa Kecamatan Cendana dalam Campuran AC-WC," Paulus Civ. Eng. J., vol. 2, no. 1, hlm. 53-57, 2020.

[7] I. M. Batara, R. Mangontan, dan Alpius, "Pemanfaatan Agregat Sungai Lamasi Kabupaten Luwu Sebagai Campuran Lapisan Aspal Beton AC-WC," Paulus Civ. Eng. J., vol. 2, no. 3, hlm. 171-179, 2020.

[8] Deamayes, Alpius, dan C. Kamba, "Pemanfaatan Batu Sungai Melli Kecamatan Baebunta Kabupaten Luwu Utara Dalam Campuran AC-WC," Paulus Civ. Eng. J., vol. 3, no. 1, hlm. 85-91, 2021, doi: https://doi.org/10.52722/pcej.v3i1.210.

[9] R. C. Ponglabba, R. Rachman, dan Alpius, "Pemanfaatan Batu Gunung Pasapak Kecamatan Bambang Kabupaten Mamasa sebagai Agregat Campuran Laston WC," Paulus Civ. Eng. J., vol. 3, no. 2, hlm. 286-293, 2021, doi: https://doi.org/10.52722/pcej.v3i2.258.

[10] A. I. E. Pakka, R. Rachman, dan Alpus, "Karakteristik Campuran Laston Lapis Antara Menggunakan Abu Jerami Sebagai Bahan Substitusi Filler," Paulus Civ. Eng. J., vol. 3, no. 3, hlm. 441-447, 2021, doi: https://doi.org/10.52722/pcej.v3i3.296.

[11] A. R. Seppo, R. Rachman, dan N. Ali, "Variasi Suhu Pemadatan Campuran AC-WC Menggunakan Batu Sungai Balusu Kabupaten Toraja Utara," J. Matriks Tek. Sipil, vol. 9, no. 1, hlm. 23-31, 2021, doi: https://doi.org/10.20961/mateksi.v9i1.49248. 